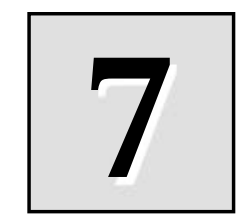

\title{
Metal Transport in the Rhizobium-Legume Symbiosis
}

\author{
M. González-Guerrero, L. Rubio-Sanz, B. Rodríguez-Haas, \\ M. Albareda, M. Menéndez-Cerón, B. Brito and J.M. Palacios*
}

\section{Introduction}

Iron, zinc, copper, molybdenum and some other transition metals are essential nutrients (Fraustro da Silva and Williams 2001). They are constitutive elements of around half of the proteins of a typical cell (Andreini et al. 2008), where they may act as structural elements, such as zinc in the zinc finger domain, but mostly as key elements in the active site of enzymes involved in almost every physiological process, from oxidative respiration to photosynthesis. These elements are growth-limiting nutrients for autotrophic organisms, since they form very stable complexes, resulting in low solubility and making their uptake difficult (Ruel and Bouis 1998, Fung et al. 2000, Grotz and Guerinot 2006). Moreover, living beings cannot accumulate high amounts of essential transition metals, since these elements can catalyze the production of free radicals in Fenton-style reactions or compete with other metals for the active site of metalloenzymes (Goldstein et al. 1993, Ranquet et al. 2007, Macomber and Imlay 2009). This is also the basis of the toxic effect of non-biogenic metals such as cadmium, lead or mercury.

Centro de Biotecnología y Genómica de Plantas. Universidad Politécnica de Madrid. Carretera M-40 k. 38. 28223 Pozuelo de Alarcón (Madrid)-Spain.

*Corresponding author: jose.palacios@upm.es 
Consequently, a concerted set of systems must be in place to ensure high affinity metal uptake while simultaneously avoiding the noxious effects derived from metal accumulation. These systems include a number of metal transporter families, several types of organic molecules that can bind metals with high affinity, soluble proteins that shuttle metal in the cytosol (metallochaperones) or that simply bind excess metals (metallothioneins), and transcription factors that regulate the process (Wandersman and Delepelaire 2004, Waldron and Robinson 2009, Blindauer and Leszczyszyn 2010, Reyes-Caballero et al. 2011, Argüello et al. 2012). Overall, the mechanisms governing metal homeostasis are so efficient that the "free", hydrated, cytosolic metal concentration of a typical bacteria is in the pMfM range (Outten and $\mathrm{O}^{\prime}$ Halloran 2001), which is less than one free ion per cell. This has two important consequences for how metals are handled by the cell: one of them is the high metal affinity of all the elements involved in metal homeostasis; the other is that metal transport involves either the cotransport with a metal ligand (nicotianamine, glutathione, ...) or the physical interaction between a metal delivery metallochaperone and the transporter itself.

In this chapter we focus on how metals are important for nitrogen fixation, and how metal uptake is carried out in the Rhizobium-legume system.

\section{Metals and Symbiotic Nitrogen Fixation}

Metal levels in the host legume are critical for the establishment and functionality of the symbiosis with rhizobia. For instance, the effect of low iron levels ranges from the inhibition of the nodulation to the loss of the capability to fix nitrogen (Tang et al. 1990, Tang et al. 1992, O'Hara 2001). This is due to the high number and relevance of metalloproteins involved in symbiotic nitrogen fixation.

Nitrogenase is one of the most abundant proteins in the symbiosome (around 10 percent) and arguably the most important enzyme of this symbiosis, since it catalyzes the conversion of $\mathrm{N}_{2}$ into $\mathrm{NH}_{4}^{+}$(Miller et al. 1993). This enzyme is a multimeric protein that contains metallic cofactors, $2 \mathrm{FeMoCo}, 2 \mathrm{P}$-clusters $\left(\mathrm{Fe}_{8} \mathrm{~S}_{7}\right)$, and one $\mathrm{Fe}_{4} \mathrm{~S}_{4}$ cluster, totalling 34 iron and two molybdenum atoms. These metal cofactors direct the reducing electrons from a ferredoxin donor (also an iron-sulfur protein) through the nitrogenase $\mathrm{Fe}_{4} \mathrm{~S}_{4}$ clusters to the P-clusters reaching the FeMoCo that would finally use them to break the triple bond in $\mathrm{N}_{2}$ (Miller et al. 1993). This is an energetically inefficient process, in which reducing power is wasted in the production of $\mathrm{H}_{2}$. To recover some of it, some rhizobia express the enzyme hydrogenase, a metalloprotein that carries a Ni-Fe cluster (O'Brian and Maier 1989, Palacios et al. 2005). 
Leghemoglobin is also expressed at high levels in the nodule (around 20 percent of the total nodular protein) (Appleby 1984). This is a hemecarrying metalloprotein, whose iron confers the characteristic reddish color to functional nodules. Leghemoglobin is responsible of sequestering $\mathrm{O}_{2^{\prime}}$ creating a microaerobic environment in which nitrogenase can function. In spite of the oxygen sensitivity of nitrogenase, the bacteroids use $\mathrm{O}_{2}$ dependent respiration to obtain most of their energy. In order to be able to function in this microaerobic environment, the bacteroid expresses a high affinity cytochrome oxidase ( $c b b_{3}$-type), whose synthesis requires a steady supply of copper (Preisig et al. 1996a, b).

Metalloproteins, such as catalase or superoxide dismutase (SOD), also play an important role in controlling reactive oxygen species (ROS) (Fridovich 1998). In the nodule, ROS are created by respiration in mitochondria and bacteroids, the direct reduction of $\mathrm{O}_{2}$ by nitrogenase, hydrogenase and ferredoxin, and the autooxidation of leghemoglobin (Puppo et al. 1981, Dalton et al. 1991). Manganese and ferric-SOD are expressed in the nitrogen fixing areas of the nodule, where they seem to be controlling ROS (Rubio et al. 2004, 2007). The relative levels of Mn-SOD or of Fe-SOD appear to be controlled by iron availability in the nodule, in such a way that as the nodule senesces and heminic iron from the leghemoglobin is released, the relative levels of Fe-SOD increase, as a means to both protect against ROS, and to sequester free iron (Rubio et al. 2007). SODs transform superoxide anion to $\mathrm{H}_{2} \mathrm{O}_{2}$, which is still toxic. This peroxide is further detoxified by iron-containing catalases (Nicholls et al. 2001), which are critical for nodulation (Jamet et al. 2003, Hanyu et al. 2008). However, low levels of $\mathrm{H}_{2} \mathrm{O}_{2}$ are necessary for infection thread development and for nod signal transduction (Jamet et al. 2007, Cárdenas et al. 2008). Consequently, catalase overexpression negatively affects the symbiosis (Jamet et al. 2007). It has been hypothesized that a $\mathrm{Cu}, \mathrm{Zn}-\mathrm{SOD}$ is responsible for producing this $\mathrm{H}_{2} \mathrm{O}_{2}$ (Rubio et al. 2004, 2007).

Therefore, metals are essential nutrients for symbiotic nitrogen fixation, playing relevant roles from the transmission of the nod factor signal to the nitrogen fixation itself. Given that they are endosymbionts, and that many of these proteins are newly synthesized in the nodule, this means that for the metal to reach the symbiosome it has to cross several barriers. First, it has to be incorporated from the soil into the epidermal cells, where they symplastically reach the endodermis. Metals are transported to the vasculature and translocated to other parts of the plant, including the nodule. Then, it has to cross back the endodermis into the nodule cortex where the plant cells will uptake them to synthesize plant-derived nodular metalloproteins. Another part, the one required for bacteroid metalloproteins synthesis, has to cross not only the plasma membrane, but also the peribacteroid membrane and the rhizobial outer and inner 
membranes. Given that biological membranes are impermeable to ions, metal transporters play an important role in delivering and controlling which and how metals reach the nodule.

\section{Metal Transporters}

Metal transport is as ancient as the first cell, and consequently many metal transporter families (CDF, ZIP or $\mathrm{P}_{\mathrm{IB}}$-ATPases) are conserved in all three domains of life. Attending to their substrate, we can classify them in two groups: those transporting metal ions and those transporting metal complexes. Similarly, the direction of transport seems to be conserved, and those families involved in loading the cytosol with metals (either from the cell surface or from an organelle lumen) do not normally export metal out of the cell and vice versa. These are the most common families of metal transporters:

\section{Metal importers}

- ZIP (Zrt1-Irt1 like Protein). They typically transport divalent metals $\left(\mathrm{Fe}^{2+}, \mathrm{Zn}^{2+}\right.$ and $\left.\mathrm{Mn}^{2+}\right)$ (Eide 2004). They are mainly responsible for iron and zinc uptake in dicotyledonous plants (Vert et al. 2002).

- Nramp (Natural Resistance-Associated Macrophage Protein). Although first discovered in macrophages, these transporters are present in all domains of life (Forbes and Gros 2001, Nevo and Nelson 2006). Their role is complementary to ZIP transporters in many instances, and share similar substrates $\left(\mathrm{Fe}^{2+}, \mathrm{Mn}^{2+}, \mathrm{Zn}^{2+}\right)($ Curie et al. 2000, Cailliatte et al. 2010).

- YSL (Yellow stripe-like). These transporters are present only in plants. Their substrate is a nicotianamine or related molecule complexed with metals (DiDonato et al. 2004). They are responsible for metal uptake from soil in monocotyledonous plants, as well as for long distance metal trafficking in both monocotyledonous and dicotyledonous plants (Curie et al. 2001, Jean et al. 2005).

- Ctr ( $\mathrm{Cu}$ transporter). This is a homotrimeric protein present only in eukaryotes (Aller and Unger 2006, Dumay et al. 2006, De Feo et al. 2009). They transport $\mathrm{Cu}^{+}$towards the cytosol, being the main copper uptake system in plants (Burkhead et al. 2009).

- MOT (Molybdenum Transporter). They are an extremely high affinity $\left(\mathrm{nM} \mathrm{k}_{\mathrm{M}}\right)$ system of molybdate import in eukaryotes (Tejada-Jiménez et al. 2007, Tomatsu et al. 2007, Tejada-Jiménez et al. 2011). In some cases, their function may be carried out by sulfate transporters (Fitzpatrick et al. 2008). 
- ABC (ATP-Binding Cassette-type). These proteins transport a wide range of substrates, including mono- and oligosaccharides, organic and inorganic ions, amino acids, peptides, iron-siderophores, metals, polyamine cations, opines and vitamins (Davidson et al. 2008). The minimal structure of the ABC systems comprises two ATP binding domains for energy transduction, and two membrane-embedded domains forming the channel across the cytoplasmic membrane, which can be encoded in just one gene or by four of them (Rea 2007, Davidson et al. 2008). Most bacterial ABC uptake systems also contain a periplasmic solute-binding protein (SBP) that provides high-affinity binding to the corresponding substrate (Imperial et al. 1998). Extensive reviews on the mechanism and structure of ATP-driven transition metal transporters have been published recently (Cui and Davidson 2011, Klein and Lewinson 2011). While in bacteria they are mostly associated with metal import, in eukaryotes they are involved in metal detoxification (Rea 2007).

- TBDT (TonB-dependent transporter). They are the outer membrane proteins present only in bacteria. Most TBDT-like proteins are known to transport iron compounds (siderophores or heme) (Wandersman and Stojiljkovic 2000).

- HupE/UreJ. These bacterial transporters are involved in $\mathrm{Ni}^{2+}$ uptake (Brito et al. 2010).

- $\mathrm{NiCoT}\left(\mathrm{Ni}^{2+}-\mathrm{Co}^{2+}\right.$ transporter). These transporters are involved in nanomolar $\mathrm{Ni}^{2+}$ and $\mathrm{Co}^{2+}$ uptake in bacteria, archaea and eukaryotes (Eitinger and Friedrich 1991, Eitinger et al. 2000).

\section{Metal exporters}

- $\mathrm{P}_{\mathrm{IB}}$-ATPases. These are members of the bigger P-type ATPase family that includes the $\mathrm{Ca}^{2+}$, the $\mathrm{Na}^{+} / \mathrm{K}^{+}$and the $\mathrm{H}^{+}$pumps (Palmgren and Nissen 2011). They are an ancient family of transporters present in all domains of life (Argüello 2003). They export $\mathrm{Cu}^{+}, \mathrm{Cu}^{2+}, \mathrm{Zn}^{2+}, \mathrm{Mn}^{2+}$, or $\mathrm{Co}^{2+}$, either with detoxification purposes or to synthesize extracytoplasmic metalloproteins (González-Guerrero et al. 2010, Argüello et al. 2011, Raimunda et al. 2011).

- CDF (Cation Diffusion Facilitator). The homodimer of these transporters extrudes divalent cations $\left(\mathrm{Zn}^{2+}, \mathrm{Fe}^{2+}\right.$, or $\left.\mathrm{Mn}^{2+}\right)$ either to the cell exterior or to organelles to synthesize metalloproteins (Blaudez et al. 2003, Anton et al. 2004, Wei et al. 2004, Lu and Fu 2007).

- Ferroportin. These transporters have been found in animals and plants (McKie et al. 2000, Morrissey et al. 2009). They are involved in $\mathrm{Fe}^{2+}$ and $\mathrm{Co}^{2+}$ delivery to the vasculature and, consequently, in long distance metal transport. 
- CCC1/VIT1. Members of this family have been found only in eukaryotes. They are involved in iron and manganese transport to the vacuole (Li et al. 2001, Kim et al. 2006).

- RND (Resistance-Nodulation-Division). These transporters are present only in Gram negative bacteria, since they form a protein complex that spans both cytoplasmic and outer membranes. The complex is formed by a trimeric inner membrane element and a trimeric outer membrane one that meets in the periplasm. This interaction is stabilized by a hexameric complex of a third protein (Long et al. 2010, Kim et al. 2011, Kulathila et al. 2011). They seem to be involved with metal detoxification from the periplasm (Anton et al. 1999, Nies 2003).

While not directly transporting metals, other transporters are also essential for metal homeostasis. Among them, probably the best characterized is the FRD3 citrate transporter in Arabidopsis thaliana (Rogers and Guerinot 2002, Durrett et al. 2007). FRD3 and its homologues are critical for iron transport across symplastically disconnected tissues (pericyclexylem, embryo-seed envelope or pollen-anther tissue) (Roschzttardtz et al. 2011).

\section{Plant Metal Uptake Transport and Symbiotic Nitrogen Fixation}

As previously stated, bioavailable metal levels in soils are very low, especially in basic soils (Grotz et al. 1998). As a consequence, plants are often in a state close to metal deficiency, affecting crop production worldwide (Grotz et al. 1998, Ruel and Bouis 1998). This is particularly evident in the case of legumes since symbiotic nitrogen fixation requires relatively high amounts of metals. Consequently, as the nodulation process is being initiated, it also triggers the "metal deficiency response" (Terry et al. 1991). In dicotyledonous plants, this response involves an acidification of the surrounding soil to increase metal solubility, and the induction of metal reductases to reduce metals which are subsequently incorporated by epidermal metal transporters and also up-regulated (Puig et al. 2007, Andaluz et al. 2009, Bernal et al. 2012). Concomitant to this, and in order to ensure that the nodule needs are satisfied, the legume should down-regulate metal transporters directing metals to non-essential roles, as it seems to be the case of MtMTP1 (Chen et al. 2009).

To date, only three plant transporters have been associated with metal transfer to the nodule. The best characterized of them is Lotus japonicus SEN1, identified in a screen for fix mutants (Hakoyama et al. 2011). SEN1 is a member of the CCC1/VIT1 family. It probably transports iron, since the nodules of $\operatorname{sen} 1$ plants have lower iron concentrations. Histochemical and transcriptional data indicate that SEN1 is nodule-specific. All these 
observations suggest that SEN1 is involved in iron delivery to the symbiosome. However, the authors of this work were not able to show the precise location of SEN1 in the cell, nor verify the metal transported. This was achieved in the other two identified nodule-specific metal transporters: the Nramp transporter GmDMT1 and the ZIP GmZIP1, both from Glycine $\max$ (Moreau et al. 2002, Kaiser et al. 2003). These transporters are located in the peribacteroid membrane. Yeast complementation assays indicate that they transport $\mathrm{Fe}^{2+}$ and $\mathrm{Zn}^{2+}$ respectively. Their precise direction of transport is not clear. The complementation data and biochemical analysis of homologous transporters indicate that they introduce metal towards the cytosol (Eide 2004, Nevo and Nelson 2006). However, in contradiction with this, an antibody raised against GmZIP1 inhibited Zn uptake in isolated symbiosomes (Moreau et al. 2002). Unfortunately, at that time it was not possible to study mutant lines of either gene, and consequently there is no data on the actual importance and role of each transporter in the symbiosis.

The nodule senesces a few weeks post infection. This is a genetically programmed process, often times coupled to flowering, in which the plant stops sending nutrients to the nodule and directs them instead to the seed (Fedorova et al. 2002, Puppo et al. 2005). It is estimated that around 50 percent of the nodular metal is transferred back to the seed (Burton et al. 1998), where it will be used for embryogenesis and germination (Sancenon et al. 2004, Kim et al. 2006, Roschzttardtz et al. 2011). Consequently, from a metal point of view, nodule senescence involves not only stopping metal delivery to the nodule but recycling the metal "stored" in the nodule. In this process, YSL transporters would play a role. As stated earlier, YSLs are involved in long-distance metal trafficking in which the metal substrate forms complexes with nicotianamine (DiDonato et al. 2004). Although no YSL transporter has as yet been identified in nodules, the presence of the nodule-specific senescence-induced nicotianamine synthase LjNAS2 indicates that this mechanism should be in place (Hakoyama et al. 2009). In this process of recycling metals, ferritins would also participate. Ferritins are plastidial iron storage proteins that form a shell-like structure that contains the iron in a quasi-crystalline form (Briat et al. 2010). In functional nodules, ferritins are highly expressed in the infected cells, but they are downregulated as the nodule senesces or in the senescence areas of indeterminate nodules (Lucas et al. 1998). This is consistent with a role of ferritin in the protection against ROS (Briat et al. 2010). However, in Lupinus nodules, as the nodule senesces, ferritins are up-regulated in the nodular cortex, which might be responsible for protecting the rest of the plant against free radicals produced in the degradation of the nodule, as well as storing the iron before to its translocation to the vasculature via YSL transporters. 


\section{Metal Transport Mechanisms in the Bacterial Side}

As already stated, the endosymbiotic state of rhizobia requires the uptake of high amounts of metals for the synthesis of metalloproteins. This has an additional layer of complexity, since these bacteria live surrounded by a plant-derived peribacteroid membrane immersed in the plant cytoplasm. Given the complexity of the symbiotic situation, most metal transport studies have been performed with free-living cultures, with further analysis of the effect that mutations in the different systems may have in symbiotic performance. We present here the main recent advances reported on rhizobial mechanisms for uptake of metals through outer and inner membranes. Metal efflux mechanisms, mainly involved in resistance against high levels of metals, have been covered in other reviews (Nies 2003, Macomber and Hausinger 2011, Raimunda et al. 2011).

\section{Metallo-organic Complexes and Metal Uptake in Rhizobia}

The extremely low solubility of iron under aerobic conditions is a problem that many organisms, including bacteria and plants, solve through the production of siderophores, organic compounds of low molecular weight (200-2000 Da) with high affinity for $\mathrm{Fe}^{3+}$ that allow the bacteria to scavenge the environment for this metal. Siderophores have a variety of chemical structures and form a family of at least 500 different compounds (Budzikiewicz 2010, Hider and Kong 2010). So far, the structures of three types of rhizobial siderophores have been characterized: cyclic trihydroxamates (vicibactin), $\alpha$-hydroxycarboxylates (rhizobactin) and citrate-derivative hydroxamates (rhizobactin 1021 and schizokinen). Genes involved in the synthesis of these siderophores have been identified for different rhizobia (see O'Brian and Fabiano 2010 for a review).

Metallophores specific for other cations could be used for metal uptake. The analysis of a novel nickel uptake system through the outer membrane of Helicobacter pylori led to the hypothesis of the existence of a nickel-complexing compound (nickelophore) required to uptake this element when present at very low concentrations (Schauer et al. 2007). The genome of Bradyrhizobium japonicum encodes a similar outer membrane receptor for nickel (see below) suggesting that this metal could also be taken as a metallophore-complex in this bacterium. On the other hand, the existence of a chalkophore (the copper metallophore methanobactin) has been described in the alphaproteobacterium Methylosinus trichosporium and other methanotrophic bacteria (Balasubramanian et al. 2011), although the presence of such systems has not been studied in rhizobia.

In addition to bacterial metallophores, rhizobia can also use other complexes such as heme and citrate for uptake of iron or other metals. 
Heme is a natural iron source for pathogenic bacteria, and it can be also used by rhizobia. Heme acquisition mediated by the $h m u$ system has been described in different rhizobia, and the use of such a system for iron uptake from leghemoglobin in senescing nodules has been proposed (Balasubramanian et al. 2011). Citrate production and uptake of iron-citrate complexes have been described in B. japonicum free-living cells (Guerinot et al. 1990). Furthermore, Moreau et al. (1995) showed that isolated soybean bacteroids were able to transport iron citrate, and proposed this chemical species as the main supply for iron in symbiotic conditions. Besides this report, information on the "chemical landscape" of metal species available to the bacteroids within the nodules is scarce. For instance, while nickel is present as malate and citrate complexes in pea nodules (Cacho et al. 2010), other legumes show a different speciation for this metal (our unpublished results). This might affect the availability of nickel for the synthesis of Nienzymes such as hydrogenase, and might account for the marked host effect observed on expression of R. leguminosarum hydrogenase metalloenzyme (Brito et al. 2008).

\section{Transporters for Metal Uptake through the Outer Membrane}

Once the metallo-organic complexes are formed outside the cell, they are internalized through specific receptors located in the outer membrane (OM). Although transport of divalent cations through OM can proceed through general porins (Zeth and Thein 2010), the low availability of metal ions in the free form implies the requirement of receptors to import metallo-organic complexes. The OM does not maintain a proton gradient nor ATP synthesis, and the energy for transport through these receptors is collected from the cytoplasmic membrane by ExbB/ExbD membrane protein complexes and transduced to the $\mathrm{OM}$ by the periplasm-spanning inner-membrane protein TonB (Postle and Larsen 2007, Noinaj et al. 2010). For this reason these receptors have been designated as TonB-dependent transporters (TBDTs). The mechanism of uptake for ferric-siderophore complexes by a TBDT has been described in detail in the E. coli model system (Chakraborty et al. 2007). Most TBDT-like proteins are known to transport iron compounds (siderophores or heme) or cobalamine (Noinaj et al. 2010); recent reports, however, indicate that these kind of receptors are also involved in the uptake of nickel (Schauer et al. 2007) and zinc (Stork et al. 2010).

In the case of rhizobia, $\mathrm{Fe}^{3+}$-siderophore complexes are recognized by different $\mathrm{OM}$ receptors depending on the siderophore. $R$. leguminosarum contains a receptor for vicibactin (FhuA) whose expression is induced in free-living cultures under low Fe conditions (Yeoman et al. 2000). Interestingly, fhuA expression is also induced in the meristematic zone of pea nodules, but not in mature bacteroids. Mutations in $f h u A$, however, do 
not show significant effects on symbiotic performance (Yeoman et al. 2000). The TBDT for Fe-rhizobactin complex is encoded by Sinorhizobium meliloti rht $A$. This gene is regulated by iron, and encodes a protein highly similar to enterobactin receptor LutA. S. meliloti rht $A^{-}$mutants have no significant defects in symbiotic performance (Lynch et al. 2001).

Genomic searches have unveiled the existence of other potential TonBdependent receptors for which there is no experimental evidence. Analysis of the genome of 13 selected Rhizobiaceae strains revealed that the number of TBDT-like genes ranged from one in Mesorhizobium loti MAFF303099 to 14 in Azorhizobium caulinodans ORS571 (Lim 2010). The majority of the 54 rhizobial TBDTs identified in that study are predicted to be involved in the uptake of iron-siderophore (26) or heme (13). Also, Mesorhizobium loti TBDT-like encoded by meso2063 is known to transport cobalamine, and B. japonicum bll6948 might transport nickel. The latter assumption is based on the similarity of the bll6948 gene product to a TBDT involved in nickel uptake in Helicobacter pylori (Schauer et al. 2007), and on the genomic context of bll6948, located between the gene encoding a nickel transporter of the NiCoT family (hupN) and a cluster of genes for the nickel-containing enzyme hydrogenase (Schauer et al. 2008). Although there are no direct studies on the relevance of this potential Ni-specific TBDT, data from transcriptomic analysis indicate that bll6948 is induced, although at low level, in B. japonicum bacteroids (Chang et al. 2007).

Some rhizobia do not produce siderophores, but do synthesize OM receptors able to bind siderophore-metal complexes, allowing the uptake of iron chelates (Small et al. 2009). Such siderophores used by one organism but synthesized and secreted by other organisms are referred to as xenosiderophores. Examples of this type are ferrichrome and rhodotorulic acid, siderophores of fungal origin used by B. japonicum as a source of iron (Plessner et al. 1993). The use of xenosiderophores in rhizobia is extensively discussed in another review (O'Brian and Fabiano 2010). A recent report demonstrated that the expression of siderophore receptors from Pseudomonas in rhizobia isolated from pigeon pea resulted in better rhizosphere colonization and improved legume plant growth (Arif et al. 2012). This data suggests that iron availability is a major factor limiting the rhizobium-legume symbiosis, and that expression of heterologous siderophore receptors might constitute a potential tool to improve competitiveness and nitrogen fixation.

Although TBDTs appear to be the major OM metal receptors, other types of OM transporters might also participate in metal uptake. Recently, an outer membrane protein with a $\beta$-barrel structure $(\mathrm{MnoP})$ has been described as essential for manganese uptake in B. japonicum (Hohle et al. 2011). This protein is similar to specific porins OmpA and OprB, and unrelated to the TBDTs described above, and might represent a distinct model for metal 
uptake through the outer membrane. The fact that the expression of this protein is co-regulated with that of the inner membrane $\mathrm{Mn}^{2+}$ transporter $\mathrm{MntH}$ strongly suggests the existence of a two-step transport system for crossing both membranes in this bacterium (Hohle et al. 2011).

\section{Mechanisms for Metal Uptake through Inner Membrane}

Once in the periplasm, metal ions must cross the cytoplasmic membrane, the major permeability barrier for metal uptake. As described above, bacteria have developed a number of mechanisms to overcome this barrier.

\section{$A B C$ Transporters}

$\mathrm{ABC}$ transporters are the prevalent transport systems in rhizobia (Young et al. 2006). S. meliloti contains 146 such systems, and similar numbers are present in other Rhizobiaceae (Galibert et al. 2001). The role of ABC transporters in the uptake of iron, manganese, cobalt, molybdenum and zinc has been demonstrated in free-living cultures of different rhizobia. Examples of iron-siderophore uptake systems include the fhuBCD system described in Rhizobium leguminosarum for uptake of vicibactin-Fe, and the hmuTUV system described in several rhizobia for heme-Fe complexes (O'Brian and Fabiano 2010).

A manganese-specific $\mathrm{ABC}$ importer (sit $A B C D$ ) has been described in S. meliloti. Analysis of $S$. meliloti mutants affected in this operon indicates that this system is required for growth under manganese-limiting conditions. The same mutants display a normal symbiotic phenotype (Platero et al. 2003). A similar situation was found for the cobalt transport system ( $c b t J K L)$ recently described also in S. meliloti (Cheng et al. 2011). Expression of this system is controlled by a cobalamin-binding riboswitch located upstream of the operon. Mutants affected in this system are unable to grow on LB medium unless it is supplemented with cobalt. Interestingly, these mutants show a residual level of cobalt uptake, potentially due to an alternate, unspecific transport system. Such a system might be responsible for the normal symbiotic phenotype showed by the $c b t$ mutants in symbiosis with alfalfa (Cheng et al. 2011).

The ModABC system mediates high affinity molybdate uptake in B. japonicum and probably also in other rhizobia, since it is encoded in most rhizobial genomes (http:/ /genome.kazusa.or.jp/rhizobase/). B. japonicum mutants affected in the mod system lack nitrate reductase activity in free living cultures, and show reduced levels of nitrogen fixation in symbiosis with soybean. These deficiencies were corrected by addition of molybdenum to the plants (Delgado et al. 2006). Such complementation has a strong dependence on the presence of sulfate, suggesting that, in addition to being 
mainly incorporated through the Mod system, molybdate is also taken up through sulfate transporters under symbiotic conditions, as it has been shown for a plant sulfate transporter (Fitzpatrick et al. 2008).

$\mathrm{ABC}$ transporters for zinc uptake homologous to the ZnuABC system described in E. coli and other bacteria (Hantke 2005) are present in the genome of most rhizobial strains. However, no specific work on zinc transport by endosymbiotic bacteria is available. The only mention of potential relevance of these transport systems in rhizobia is the induction of expression of S. meliloti Znu system in response to zinc limitation (Mauchline et al. 2006). Interestingly, Znu-deficient mutants of the phylogenetically relative animal pathogen Brucella abortus show a reduced intracellular survival and virulence (Kim et al. 2004).

There is not much information about the uptake of copper in rhizobia. Copper is required in bacteria mainly for proteins located either in the cytoplasmic membrane or in the periplasmic space. Based on that, some authors maintain that bacteria may not have a general requirement for cytoplasmic copper (Solioz et al. 2010). However, genes for two ATPdependent systems (nosDFYL and fixI) have been linked to copper metabolism in rhizobia. The nosDFYL operon encodes an ABC uptake system. Since these genes are located in the nitrous oxide reductase gene clusters from S. meliloti and B. japonicum (Holloway et al. 1996, Velasco et al. 2004), their participation in the uptake of copper for the synthesis of this copper-metalloenzyme has been proposed (Holloway et al. 1996). Mutations in these genes do not affect symbiotic performance, suggesting that such a system is not critical for copper uptake under symbiotic conditions. On the other hand, fixI encodes a P-type Cu-ATPase known to participate in the synthesis of $\mathrm{Cbb}_{3}$-type heme-copper cytochrome $c$ oxidase ( $c b b_{3}$-Cox), an essential component of the symbiotic respiratory branch (Preisig et al. 1996a). These authors suggested the possibility that this ATPase imports $\mathrm{Cu}$ into the cytoplasm; however, this possibility has been contested by biochemical data that indicates that FixI is actually an efflux system (González-Guerrero et al. 2010). Then, FixI should participate in the transport of $\mathrm{Cu}$ from cytoplasm to periplasm for $\mathrm{Cbb}_{3}$-Cox biosynthesis. Copper uptake for $\mathrm{Cbb}_{3}$-Cox synthesis in rhizobia might instead be carried out by CcoA, an MFS transporter recently described in Rhodobacter capsulatus (see below).

\section{Permease Metal Transporters}

These are secondary transporters, dependent on proton motive force, composed by single proteins with multiple transmembrane domains in a monomeric or dimeric form. In the case of endosymbiotic bacteria, this type of transport system mediates uptake of nickel, cobalt and manganese ions. 
Three main classes of secondary transport mechanisms for metal uptake have been described in rhizobia:

- NiCoTs. NiCoTs expression in E. coli identified ion preferences ranging from strict selectivity for nickel to a strong preference for cobalt through unbiased transport of both ions (Eitinger et al. 2005). B. japonicum HupN was the first member identified in rhizobia (Fu et al. 1994). The corresponding gene is located adjacent to a DNA region encoding the nickel-containing enzyme hydrogenase. Analysis of mutants affected in this gene revealed a significant $\mathrm{Ni}$-dependent decrease in hydrogenase activity in free-living cells (Fu et al. 1994).

- HupE/UreJ. Their encoding genes are associated to gene clusters encoding NiFe hidrogenases in different rhizobia like R. leguminosarum and $A$. caulinodans. R. leguminosarum hupE encodes an integral membrane protein with six known transmembrane domains. Mutant analysis demonstrated the essentiality of this protein for the synthesis of $R$. leguminosarum NiFe hydrogenase both in free-living culture and in symbiosis (Brito et al. 2010). Genes encoding members of this group of transporters in other bacteria are sometimes preceded by sequences for cobalamin riboswitch RNA regulatory elements, suggesting that they might transport this cobalt compound rather than nickel (Schauer et al. 2008). So far, no evidence for a cobalt transporter of this type has been reported in rhizobia.

- Nramp. A relevant member of this group is $\mathrm{MntH}$, a proton symporter acting as the main manganese uptake system in free-living cultures of B. japonicum (Hohle and O'Brian 2009). This transporter is not essential for the development of nodules nor for nitrogen fixation activity in symbiosis with soybean, suggesting that either the host provides enough manganese to make high-affinity transport unnecessary, or the bacterium has another mechanism for manganese acquisition that is not expressed in free-living cells (Hohle and O'Brian 2009). Interestingly, $\mathrm{MntH}$ plays a critical role in $\mathrm{Mn}^{2+}$ transport in the close phylogenetic relative $B$. abortus, where the presence of this manganese transporter is required for wild-type virulence in mouse (Anderson et al. 2009).

An additional type of secondary metal transporter might be relevant for rhizobia. A recent report described a gene $(c c 0 A)$ required to maintain normal amounts of intracellular $\mathrm{Cu}$ and synthesis of $\mathrm{Cbb}_{3}$-Cox (Ekici et al. 2012) in the alpha-proteobacterium Rhodobacter capsulatus, strongly suggesting that the corresponding protein is a copper uptake transporter. CcoA is a member of the major facilitator superfamily (MFS) with 12 putative transmembrane helices split into two subdomains of six helices each, separated by a large cytoplasmic loop. Interestingly, this protein has homologs ( $c a$. 40 percent identity) encoded in the genome of Bradyrhizobium, Mesorhizobium and 
Sinorhizobium. Further studies are required to elucidate whether these homologs might function as copper transporters in rhizobia.

\section{Global Analysis of Expression of Bacterial Metal Uptake Systems}

The information on direct analysis of metal transport under symbiotic conditions is still scarce, due to the inherent difficulty of working with bacteroids. This information can be complemented by data arising form transcriptomic and proteomic analysis of genes expressed by rhizobia in the endosymbiotic state. A global study performed through transcriptomic analysis of symbiotic expression in S. meliloti revealed that genes involved in iron uptake were mostly repressed in the bacteroids (Becker et al. 2004). However, repression does not indicate that these genes are not expressed in the nodule bacteria. In fact, solute-binding proteins from $A B C$ systems mediating uptake of iron, manganese and zinc were identified in the proteomic analysis of $S$. meliloti bacteroids isolated from alfalfa nodules (Djordjevic et al. 2003). In the case of B. japonicum soybean bacteroids, transcriptomic analysis (Pessi et al. 2007) revealed that components of the molybdenum uptake system ModABC were amongst the most strongly induced genes in bacteroids (over 120-fold as compared to free-living cells). This data is consistent with the relevant symbiotic role of this transporter deduced from the mutant analysis mentioned above (Delgado et al. 2006). Further proteomic analyses of $B$. japonicum bacteroids induced in soybean indicate the presence of proteins involved in iron transport, including the TonB-dependent ferrichrome receptors blr3904 and bll4920 (Delmotte et al. 2010). Finally, a recent report on the transcriptomics of $R$. etli bacteroids induced in Phaseolus indicates moderate induction of genes for inorganic ion transporters including afu $A 3$, which encodes a solute binding protein from an $A B C$ iron uptake system not expressed in free-living cells (Vercruysse et al. 2011).

\section{Summary and Outlook}

In the last two decades, our understanding of metal homeostasis processes in plants and bacteria has increased considerably, but it is still lagging in certain aspects such as the legume-rhizobium interaction. This is in spite of metals being essential nutrients for symbiotic nitrogen fixation and critical components of the key enzymes of this metabolic process. In this process of metal exchange between the symbionts, the peribacteroid membrane is critical. However, many transporters in this membrane remain to be discovered. With the development of genomic, transcriptomic, proteomic and metallomic tools we are filling this gap in knowledge. New elements involved in metal transfer to the symbiosome have been identified, as well 
as the mechanisms involved in bacteroid metal uptake and use (summarized in Fig. 7.1). Interestingly, not many of the rhizobial transporters involved in metal uptake in free living conditions have a relevant role in symbiosis, probably reflecting a more favorable environment for metal uptake than in soils. Nevertheless, there are still many aspects to study, such as how the overall plant metal homeostasis mechanisms are affected by nodulation, what role rhizobial metal efflux transporters play in the invasion stage, which transporters are directing metals from the soil to the bacteroid, how metal speciation affects metal delivery, and how metals are directed to the corresponding apoproteins in the bacteroid cytosol.

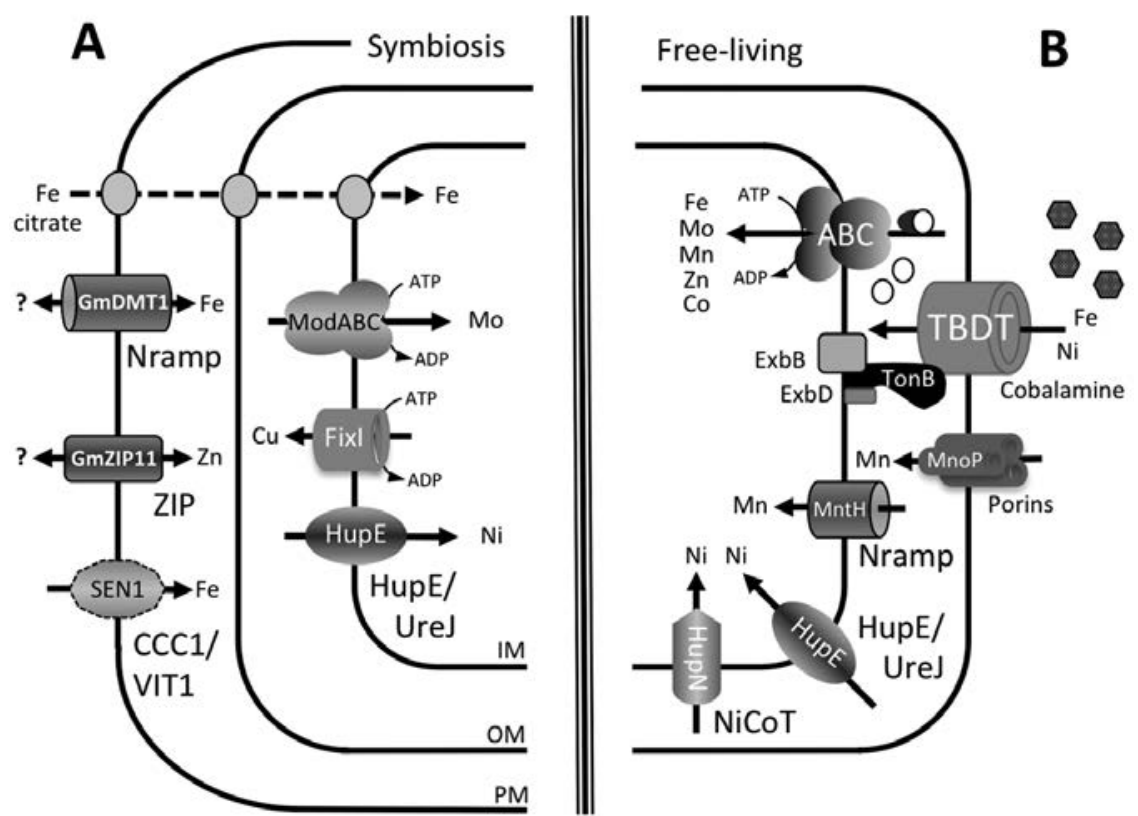

Figure 7.1 Metal uptake transporters described in Rhizobium-legume interactions. Transporters involved in metal uptake in symbiotic (A) and free-living (B) conditions are localized in the inner (IM), outer (OM) and plant membranes (PM). Siderophores are shown by hexagons whereas circles represent metal ions. Transport orientation for the plant Nramp and ZIP proteins remains elusive. The dotted arrow symbolizes an unknown mechanism for ferric citrate transfer across the plant and bacterial membranes. ABC: ATP-Binding Cassette transporters.

\section{Acknowledgements}

The work at the author's laboratories was funded by grants from Spain's Ministry of Science and Innovation (BIO2010-15301 to J.M.Palacios) and from the European Union Marie Curie International Reintegration program 
(FP7-PEOPLE-2010-RG-276771 to M.González-Guerrero). M.GonzálezGuerrero is a recipient of a Ramón y Cajal research contract. M.MenéndezCerón is a recipient of a grant from CONACYT (México).

\section{References}

Aller, S.G. and V.M. Unger. 2006. Projection structure of the human copper transporter CTR1 at 6-A resolution reveals a compact trimer with a novel channel-like architecture. Proc. Natl. Acad. Sci. U.S.A. 103: 3627-3632.

Andaluz, S., J. Rodríguez-Celma, A. Abadía, J. Abadía and A.F. López-Millán. 2009. Time course induction of several key enzymes in Medicago truncatula roots in response to $\mathrm{Fe}$ deficiency. Plant Physiol. Biochem. 47: 1082-1088.

Anderson, E.S., J.T. Paulley, J.M. Gaines, M.W. Valderas, D.W. Martin, E. Menscher, T.D. Brown, C.S. Burns and R.M. Roop, 2nd. 2009. The manganese transporter MntH is a critical virulence determinant for Brucella abortus 2308 in experimentally infected mice. Infect. Immun. 77: 3466-3474.

Andreini, C., I. Bertini, G. Cavallaro, G. Holliday and J. Thornton. 2008. Metal ions in biological catalysis: from enzyme databases to general principles. J. Biol. Inorg. Chem. 13: 1205-1218.

Anton, A., C. Groe, J. Reiman, T. Probyl and D.H. Nies. 1999. CzcD is a heavy metal ion transporter involved in regulation of heavy metal resistance in Ralstonia sp. strain CH34. J. Bacteriol. 181: 6876-6881.

Anton, A., A. Weltrowski, C.J. Haney, S. Franke, G. Grass, C. Rensing and D.H. Nies. 2004. Characteristics of zinc transport by two bacterial cation diffusion facilitators from Ralstonia metallidurans CH34 and Escherichia coli. J. Bacteriol. 186: 7499-7507.

Appleby, C.A. 1984. Leghemoglobin and Rhizobium respiration. Annu. Rev. Plant Physiol. 35: $443-478$.

Argüello, J.M. 2003. Identification of ion-selectivity determinants in heavy-metal transport P-1B-type ATPases. J. Membrane Biol. 195: 93-108.

Argüello, J.M., M. González-Guerrero and D. Raimunda. 2011. Bacterial transition metal P1BATPases: Transport mechanism and roles in virulence. Biochemistry. 50: 9940-9949.

Argüello, J.M., D. Raimunda and M. González-Guerrero. 2012. Metal transport across biomembranes: Emerging models for a distinct chemistry. J. Biol. Chem. 287: 13510-13517.

Arif, K., G. Archana and J. Desai Anjana. 2012. Engineering heterologous iron siderophore complex utilization in rhizobia: Effect on growth of peanut and pigeon pea plants. Appl. Soil Ecol. 53: 65-73.

Balasubramanian, R., G.E. Kenney and A.C. Rosenzweig. 2011. Dual pathways for copper uptake by methanotrophic bacteria. J. Biol. Chem. 286: 37313-37319.

Becker, A., H. Berges, E. Krol, C. Bruand, S. Ruberg, D. Capela, E. Lauber, E. Meilhoc, F. Ampe, F.J. de Bruijn, J. Fourment, A. Francez-Charlot, D. Kahn, H. Kuster, C. Liebe, A. Puhler, S. Weidner and J. Batut. 2004. Global changes in gene expression in Sinorhizobium meliloti 1021 under microoxic and symbiotic conditions. Mol. Plant Microbe Interact. 17: 292-303.

Bernal, M., D. Casero, V. Singh, G.T. Wilson, A. Grande, H. Yang, S.C. Dodani, M. Pellegrini, P. Huijser, E.L. Connolly, S.S. Merchant and U. Krämer. 2012. Transcriptome sequencing identifies SPL7-regulated copper acquisition genes FRO4/FRO5 and the copper dependence of iron homeostasis in Arabidopsis. Plant Cell. 24: 738-761.

Blaudez, D., A. Kohler, F. Martin, D. Sanders and M. Chalot. 2003. Poplar metal tolerance protein 1 confers zinc tolerance and is an oligomeric vacuolar zinc transporter with an essential leucine zipper motif. Plant Cell. 15: 2911-2928. 
Blindauer, C.A. and O.I. Leszczyszyn. 2010. Metallothioneins: unparalleled diversity in structures and functions for metal ion homeostasis and more Nat. Prod. Rep. 27: 720-741.

Briat, J.F., C. Duc, K. Ravet and F. Gaymard. 2010. Ferritins and iron storage in plants. Biochim. Biophys. Acta. 1800: 806-814.

Brito, B., A. Toffanin, R.-I. Prieto, J. Imperial, T. Ruiz-Argüeso and J.M. Palacios. 2008. Hostdependent expression of Rhizobium leguminosarum bv. viciae hydrogenase is controlled at transcriptional and post-transcriptional levels in legume nodules. Mol. Plant Microbe. Interact. 21: 597-604.

Brito, B., R.-I. Prieto, E. Cabrera, M.-A. Mandrand-Berthelot, J. Imperial, T. Ruiz-Argueso and J.-M. Palacios. 2010. Rhizobium leguminosarum hupE encodes a nickel transporter required for hydrogenase activity. J. Bacteriol. 192: 925-935.

Budzikiewicz, H. 2010. Microbial siderophores. Fortschr Chem. Org. Naturst. 92: 1-75.

Burkhead, J.L., K.A. Gogolin Reynolds, S.E. Abdel-Ghany, C.M. Cohu and M. Pilon. 2009. Copper homeostasis. New Phytol. 182: 799-816.

Burton, J.W., C. Harlow and E.C. Theil. 1998. Evidence for reutilization of nodule iron in soybean seed development. J. Plant Nutr. 5: 913-927.

Cacho, C., B. Brito, J. Palacios, C. Pérez-Conde and C. Cámara. 2010. Speciation of nickel by HPLC-UV/MS in pea nodules. Talanta. 83: 78-83.

Cailliatte, R., A. Schikora, J.F. Briat, S. Mari and C. Curie. 2010. High-affinity manganese uptake by the metal transporter NRAMP1 is essential for Arabidopsis growth in low manganese conditions. Plant Cell. 22: 904-917.

Cárdenas, L., A. Martínez, F. Sánchez and C. Quinto. 2008. Fast, transient and specific intracellular ROS changes in living root hair cells responding to Nod factors (NFs). Plant J. 56: 802-813.

Chakraborty, R., E. Storey and D. van der Helm. 2007. Molecular mechanism of ferric siderophore passage through the outer membrane receptor proteins of Escherichia coli. Biometals. 20: 263-274.

Chang, W.S., W.L. Franck, E. Cytryn, S. Jeong, T. Joshi, D.W. Emerich, M.J. Sadowsky, D. Xu and G. Stacey. 2007. An oligonucleotide microarray resource for transcriptional profiling of Bradyrhizobium japonicum. Mol. Plant Microbe Interact. 20: 1298-1307.

Chen, M., X. Shen, D. Li, L. Ma, J. Dong and T. Wang. 2009. Identification and characterization of MtMTP1, a Zn transporter of CDF family, in the Medicago truncatula. Plant Physiol. Biochem. 47: 1089-1094.

Cheng, J., B. Poduska, R.A. Morton and T.M. Finan. 2011. An ABC-type cobalt transport system is essential for growth of Sinorhizobium meliloti at trace metal concentrations. J. Bacteriol. 193: 4405-4416.

Cui, J. and A.L. Davidson. 2011. ABC solute importers in bacteria. Essays Biochem. 50: 85-99.

Curie, C., J.M. Alonso, M. Le Jean, J.R. Ecker and J.F. Briat. 2000. Involvement of NRAMP1 from Arabidopsis thaliana in iron transport. Biochem. J. 347: 749-755.

Curie, C., Z. Panaviene, C. Loulergue, S.L. Dellaporta, J.F. Briat and E.L. Walker. 2001. Maize yellow stripe1 encodes a membrane protein directly involved in Fe(III) uptake. Nature. 409: 346-349.

Dalton, D.A., C.J. Post and L. Langeberg. 1991. Effects of ambient oxygen and of fixed nitrogen on concentrations of glutathione, ascorbate and associated enzymes in soybean root nodules. Plant Physiol. 96: 812-818.

Davidson, A.L., E. Dassa, C. Orelle and J. Chen. 2008. Structure, function, and evolution of bacterial ATP-binding cassette systems. Microbiol. Mol. Biol. Rev. 72: 317-364, table of contents.

De Feo, C.J., S.G. Aller, G.S. Siluvai, N.J. Blackburn and V.M. Unger. 2009. Three-dimensional structure of the human copper transporter hCTR1. Proc. Natl. Acad. Sci. U.S.A. 106: 4237-4242. 


\section{Beneficial Plant-microbial Interactions}

Delgado, M.J., A. Tresierra-Ayala, C. Talbi and E.J. Bedmar. 2006. Functional characterization of the Bradyrhizobium japonicum $\bmod A$ and $\operatorname{modB}$ genes involved in molybdenum transport. Microbiology. 152: 199-207.

Delmotte, N., C.H. Ahrens, C. Knief, E. Qeli, M. Koch, H.M. Fischer, J.A. Vorholt, H. Hennecke and G. Pessi. 2010. An integrated proteomics and transcriptomics reference data set provides new insights into the Bradyrhizobium japonicum bacteroid metabolism in soybean root nodules. Proteomics. 10: 1391-1400.

DiDonato, R.J., L.A. Roberts, T. Sanderson, R.B. Eisley and E.L. Walker. 2004. Arabidopsis Yellow Stripe-Like2 (YSL2) a metal-regulated gene encoding a plasma membrane transporter of nicotianamine-metal complexes. Plant J. 39: 403-414.

Djordjevic, M.A., H.C. Chen, S. Natera, G. Van Noorden, C. Menzel, S. Taylor, C. Renard, O. Geiger and G.F. Weiller. 2003. A global analysis of protein expression profiles in Sinorhizobium meliloti: discovery of new genes for nodule occupancy and stress adaptation. Mol. Plant Microbe Interact. 16: 508-524.

Dumay, Q.C., A.J. Debut, N.M. Mansour and M.H. Saier. 2006. The copper transporter (Ctr) family of $\mathrm{Cu}^{+}$uptake systems. J. Mol. Microbiol. Biotechnol. 11: 10-19.

Durrett, T.P., W. Gassmann and E.E. Rogers. 2007. The FRD3-Mediated efflux of citrate into the root vasculature is Necessary for efficient iron translocation. Plant Physiol. 144: 197-205.

Eide, D. 2004. The ABC of solute carriers. The SLC39 family of metal ion transporters. Eur. J. Physiol. 447: 796-800.

Eitinger, T. and B. Friedrich. 1991. Cloning, nucleotide sequence, and heterologous expression of a high-affinity nickel transport gene from Alcaligenes eutrophus. J. Biol. Chem. 266: 3222-3227.

Eitinger, T., O. Degen, U. Böhnke and M. Müller. 2000. Nic1p, a relative of bacterial transition metal permeases in Schizosaccharomyces pombe, provides nickel ion for urease biosynthesis. J. Biol. Chem. 275: 18029-18033.

Eitinger, T., J. Suhr, L. Moore and J.A. Smith. 2005. Secondary transporters for nickel and cobalt ions: theme and variations. Biometals. 18: 399-405.

Ekici, S., H. Yang, H.G. Koch and F. Daldal. 2012. Novel transporter required for biogenesis of cbb3-type cytochrome c oxidase in Rhodobacter capsulatus. MBio 3.

Fedorova, M., J. van de Mortel, P.A. Matsumoto, J. Cho, C.D. Town, K.A. VandenBosch, J.S. Gantt and C.P. Vance. 2002. Genome-wide identification of nodule-specific transcripts in the model legume Medicago truncatula. Plant Physiol. 130: 519-537.

Fitzpatrick, K.L., S.D. Tyerman and B.N. Kaiser. 2008. Molybdate transport through the plant sulphate transporter SHST1. FEBS Lett. 582: 1508-1513.

Forbes, J.R. and P. Gros. 2001. Divalent-metal transport by NRAMP proteins at the interface of host-pathogen interactions. Trends Microbio. 19: 397-403.

Fraustro da Silva, J.J.R. and R.J.P. Williams. 2001. The Biological Chemistry of the Elements Oxford University Press.

Fridovich, I. 1998. Oxygen toxicity: a radical explanation. J. Exp. Biol. 201: 1203-1209.

$\mathrm{Fu}, \mathrm{C}$., S. Javedan, F. Moshiri and R.J. Maier. 1994. Bacterial genes involved in incorporation of nickel into a hydrogenase enzyme. Proc. Natl. Acad. Sci. U.S.A. 91: 5099-5103.

Fung, I.Y., S.K. Meyn, I. Tegen, S.C. Doney, J.G. John and J.K.B. Bishop. 2000. Iron supply and demand in the upper ocean. Global Biogeochem. Cycles. 14: 281-295.

Galibert, F., T.M. Finan, S.R. Long, A. Puhler, P. Abola, F. Ampe, F. Barloy-Hubler, M.J. Barnett, A. Becker, P. Boistard, G. Bothe, M. Boutry, L. Bowser, J. Buhrmester, E. Cadieu, D. Capela, P. Chain, A. Cowie, R.W. Davis, S. Dreano, N.A. Federspiel, R.F. Fisher, S. Gloux, T. Godrie, A. Goffeau, B. Golding, J. Gouzy, M. Gurjal, I. Hernandez-Lucas, A. Hong, L. Huizar, R.W. Hyman, T. Jones, D. Kahn, M.L. Kahn, S. Kalman, D.H. Keating, E. Kiss, C. Komp, V. Lelaure, D. Masuy, C. Palm, M.C. Peck, T.M. Pohl, D. Portetelle, B. Purnelle, U. Ramsperger, R. Surzycki, P. Thebault, M. Vandenbol, F.J. Vorholter, S. Weidner, D.H. Wells, K. Wong, K.C. Yeh and J. Batut. 2001. The composite genome of the legume symbiont Sinorhizobium meliloti. Science. 293: 668-672. 
Goldstein, S., D. Meyerstein and G. Czapski. 1993. The Fenton reagents. Free radical biology and medicine. 15: 435-445.

González-Guerrero, M., D. Raimunda, X. Cheng and J.M. Argüello. 2010. Distinct functional roles of homologous $\mathrm{Cu}^{+}$efflux ATPases in Pseudomonas aeuginosa. Mol. Microbiol. 78: $1246-1258$

Grotz, N. and M.L. Guerinot. 2006. Molecular aspects of Cu, Fe and Zn homeostasis in plants. Biochim. Biophys. Acta. 1763: 595-608.

Grotz, N., T. Fox, E. Connolly, W. Park, M.L. Guerinot and D. Eide. 1998. Identification of a family of zinc transporter genes from Arabidopsis that respond to zinc deficiency. Proc. Natl. Acad. Sci. U.S.A. 95: 7220-7224.

Guerinot, M.L., E.J. Meidl and O. Plessner. 1990. Citrate as a siderophore in Bradyrhizobium japonicum. J. Bacteriol. 172: 3298-3303.

Hakoyama, T., H. Watanabe, J. Tomita, A. Yamamoto, S. Sato, Y. Mori, H. Kouchi and N. Suganuma. 2009. Nicotianamine synthase specifically expressed in root nodules of Lotus japonicus. Planta. 230: 309-317.

Hakoyama, T., K. Niimi, T. Yamamoto, S. Isobe, S. Sato, Y. Nakamura, S. Tabata, H. Kumagai, Y. Umehara, K. Brossuleit, T.R. Petersen, N. Sandal, J. Stougaard, M.K. Udvardi, M. Tamaoki, M. Kawaguchi, H. Kouchi and N. Suganuma. 2011. The integral membrane protein SEN1 is required for symbiotic nitrogen fixation in Lotus japonicus nodules. Plant Cell Physiol. 53: 225-236.

Hantke, K. 2005. Bacterial zinc uptake and regulators. Curr. Opin. Microbiol. 8: 196-202.

Hanyu, M., H. Fujimoto, K. Tejima and K. Saeki. 2008. Functional differences of two distinct catalases in Mesorhizobium loti MAFF303099 under free-living and symbiotic conditions. J. Bacteriol. 191: 1463-1471.

Hider, R.C. and X. Kong. 2010. Chemistry and biology of siderophores. Nat. Prod. Rep. 27: 637-657.

Hohle, T.H. and M.R. O'Brian. 2009. The $m n t H$ gene encodes the major $\mathrm{Mn}(2+)$ transporter in Bradyrhizobium japonicum and is regulated by manganese via the Fur protein. Mol. Microbiol. 72: 399-409.

Hohle, T.H., W.L. Franck, G. Stacey and M.R. O'Brian. 2011. Bacterial outer membrane channel for divalent metal ion acquisition. Proc. Natl. Acad. Sci. U.S.A. 108: 15390-15395.

Holloway, P., W. McCormick, R.J. Watson and Y.K. Chan. 1996. Identification and analysis of the dissimilatory nitrous oxide reduction genes, nosRZDFY, of Rhizobium meliloti. J. Bacteriol. 178: 1505-1514.

Imperial, J., M. Hadi and N.K. Amy. 1998. Molybdate binding by ModA, the periplasmic component of the Escherichia coli mod molybdate transport system. Biochim. Biophys. Acta. 1370: 337-346.

Jamet, A., S. Sigaud, G. van de Sype, A. Puppo and D. Hérouart. 2003. Expression of the bacterial catalase genes during Sinorhizobium meliloti-Medicago sativa symbiosis and their crucial role during the infection process. Mol. Plant Microbe Interact. 16: 217.

Jamet, A., K. Mandon, A. Puppo and D. Hérouart. 2007. $\mathrm{H}_{2} \mathrm{O}_{2}$ Is required for optimal establishment of the Medicago sativa/Sinorhizobium meliloti symbiosis. J. Bacteriol. 189: 8741-8745.

Jean, M.L., A. Schikora, S. Mari, J.F. Briat and C. Curie. 2005. A loss-of-function mutation in AtYSL1 reveals its role in iron and nicotianamine seed loading. Plant J. 44: 769-782.

Kaiser, B.N., S. Moreau, J. Castelli, R. Thomson, A. Lambert, S. Bogliolo, A. Puppo and D.A. Day. 2003. The soybean NRAMP homologue, GmDMT1, is a symbiotic divalent metal transporter capable of ferrous iron transport. Plant J. 35: 295-304.

Kim, E.-H., D.H. Nies, M.M. McEvoy and C. Rensing. 2011. Switch or funnel: How RND-type transport systems control periplasmic metal homeostasis. J. Bacteriol. 193: 2381-2387.

Kim, S., K. Watanabe, T. Shirahata and M. Watarai. 2004. Zinc uptake system (znuA locus) of Brucella abortus is essential for intracellular survival and virulence in mice. J. Vet. Med. Sci. 66: 1059-1063. 


\section{Beneficial Plant-microbial Interactions}

Kim, S.A., T. Punshon, A. Lanzirotti, L. Li, J.M. Alonso, J.R. Ecker, J. Kaplan and M.L. Guerinot. 2006. Localization of iron in Arabidopsis seed requires the vacuolar membrane transporter VIT1. Science. 314: 1295-1298.

Klein, J.S. and O. Lewinson. 2011. Bacterial ATP-driven transporters of transition metals: physiological roles, mechanisms of action, and roles in bacterial virulence. Metallomics. 3: 1098-1108.

Kulathila, R., R. Kulathila, M. Indic and B. van den Berg. 2011. Crystal structure of Escherichia coli CusC, the outer membrane component of a heavy metal efflux pump. PLoS ONE 6: e15610.

Li, L., O.S. Chen, D. McVey Ward and J. Kaplan. 2001. CCC1 is a transporter that mediates vacuolar iron storage in yeast. J. Biol. Chem. 276: 29515-29519.

Lim, B.L. 2010. TonB-dependent receptors in nitrogen-fixing nodulating bacteria. Microbes Environ. 25: 67-74.

Long, F., C.C. Su, M.T. Zimmermann, S.E. Boyken, K.R. Rajashankar, R.L. Jernigan and E.W. Yu. 2010. Crystal structures of the CusA efflux pump suggest methionine-mediated metal transport. Nature. 467: 484-488.

Lu, M. and D. Fu. 2007. Structure of the Zinc Transporter YiiP. Science. 317: 1746-1748.

Lucas, M.M., G. Van de Sype, D. Hérouart, M.J. Hernández, A. Puppo and M.R. de Felipe. 1998. Immunolocalization of ferritin in determinate and indeterminate legume root nodules. Protoplasma. 204: 61-70.

Lynch, D., J. O'Brien, T. Welch, P. Clarke, P.O. Cuiv, J.H. Crosa and M. O'Connell. 2001. Genetic organization of the region encoding regulation, biosynthesis, and transport of rhizobactin 1021, a siderophore produced by Sinorhizobium meliloti. J. Bacteriol. 183: 2576-2585.

Macomber, L. and J.A. Imlay. 2009. The iron-sulfur clusters of dehydratases are primary intracellular targets of copper toxicity. Proc. Natl. Acad. Sci. U.S.A. 106: 8344-8349.

Macomber, L. and R.P. Hausinger. 2011. Mechanisms of nickel toxicity in microorganisms. Metallomics. 3: 1153-1162.

Mauchline, T.H., J.E. Fowler, A.K. East, A.L. Sartor, R. Zaheer, A.H. Hosie, P.S. Poole and T.M. Finan. 2006. Mapping the Sinorhizobium meliloti 1021 solute-binding proteindependent transportome. Proc. Natl. Acad. Sci. U.S.A. 103: 17933-17938.

McKie, A.T., P. Marciani, A. Rolfs, K. Brennan, K. Wehr, D. Barrow, S. Miret, A. Bomford, T.J. Peters, F. Farzaneh, M.A. Hediger, M.W. Hentze and R.J. Simpson. 2000. A novel duodenal iron-regulated transporter, IREG1, implicated in the basolateral transfer of iron to the circulation. Mol. Cell. 5: 299-309.

Miller, R.W., Z. Yu and C.G. Zarkadas. 1993. The nitrogenase proteins of Rhizobium meliloti: purification and properties of the MoFe and Fe components. Biochim. Biophys. Acta. 1163: 31-41.

Moreau, S., J.M. Meyer and A. Puppo. 1995. Uptake of iron by symbiosomes and bacteroids from soybean nodules. FEBS Lett. 361: 225-228.

Moreau, S., R.M. Thomson, B.N. Kaiser, B. Trevaskis, M.L. Guerinot, M.K. Udvardi, A. Puppo and B.A. Day. 2002. GmZIP1 encodes a symbiosis-specific zinc transporter in soybean. J. Biol. Chem. 277: 4738-4746.

Morrissey, J., I.R. Baxter, J. Lee, L. Li, B. Lahner, N. Grotz, J. Kaplan, D.E. Salt and M.L. Guerinot. 2009. The ferroportin metal efflux proteins function in iron and cobalt homeostasis in Arabidopsis. Plant Cell. 21: 3326-3338.

Nevo, Y. and N. Nelson. 2006. The NRAMP family of metal-ion transporters. Biochim. Biophys. Acta. 1763: 609-620.

Nicholls, P., I. Fita and P.C. Lowen. 2001. Enzymology and structure of catalases. Adv. Inorg. Chem. 51: 51-106.

Nies, D.H. 2003. Efflux-mediated heavy metal resistance in prokaryotes. FEMS Microbiol Rev. 27: 313-339.

Noinaj, N., M. Guillier, T.J. Barnard and S.K. Buchanan. 2010. TonB-dependent transporters: regulation, structure, and function. Annu. Rev. Microbiol. 64: 43-60. 
O'Brian, M.R. and R.J. Maier. 1989. Hydrogen metabolism in Rhizobium: energetics, regulation, enzymology and genetics. Adv. Microb. Physiol. 1988: 1-52.

O'Brian, M.R. and E. Fabiano. 2010. Mechanisms and regulation of iron homeostasis in rhizobia. In: N.S. Iacobellis, A. Collmer, S.W. Hutcheson, J.M. Mansfield, C.E. Morris, J. Murillo, N.W. Schaad, D.E. Stead, G. Surico and M. Ullrich [eds.]. Iron uptake and homeostasis in microorganisms. Kluwer Academic Caister Academic Presss, Dordrecht, The Netherlands.

O'Hara, G.W. 2001. Nutritional constraints on root nodule bacteria affecting symbiotic nitrogen fixation: a review. Austr. J. Exp. Agric. 41: 417-433.

Outten, C.E. and T.V. O'Halloran. 2001. Femtomolar sensitivity of metalloregulatory proteins controlling zinc homeostasis. Science. 292: 2488-2492.

Palacios, J.M., H. Manyani, M. Martinez, A.C. Ureta, B. Brito, E. Bascones, L. Rey, J. Imperial and T. Ruiz-Argueso. 2005. Genetics and biotechnology of the H(2)-uptake [NiFe] hydrogenase from Rhizobium leguminosarum bv. viciae, a legume endosymbiotic bacterium. Biochem. Soc. Trans. 33: 94-96.

Palmgren, M.G. and P. Nissen. 2011. P-type ATPases. Annu. Rev. Biophys. 40: 243-266.

Pessi, G., C.H. Ahrens, H. Rehrauer, A. Lindemann, F. Hauser, H.M. Fischer and H. Hennecke. 2007. Genome-wide transcript analysis of Bradyrhizobium japonicum bacteroids in soybean root nodules. Mol. Plant Microbe Interact. 20: 1353-1363.

Platero, R.A., M. Jaureguy, F.J. Battistoni and E.R. Fabiano. 2003. Mutations in sit B and sit D genes affect manganese-growth requirements in Sinorhizobium meliloti. FEMS Microbiol. Lett. 218: 65-70.

Plessner, O., T. Klapatch and M.L. Guerinot. 1993. Siderophore utilization by Bradyrhizobium japonicum. Appl. Environ. Microbiol. 59: 1688-1690.

Postle, K. and R.A. Larsen. 2007. TonB-dependent energy transduction between outer and cytoplasmic membranes. Biometals. 20: 453-465.

Preisig, O., R. Zufferey and H. Hennecke. 1996a. The Bradyrhizobium japonicum fixGHIS genes are required for the formation of the high-affinity $\mathrm{cbb}(3)$-type cytochrome oxidase. Arch. Microbiol. 165: 297-305.

Preisig, O., R. Zufferey, L. Thony-Meyer, C. Appleby and H. Hennecke. 1996b. A high-affinity $c b b 3$-type cytochrome oxidase terminates the symbiosis-specific respiratory chain of Bradyrhizobium japonicum. J. Bacteriol. 178: 1532-1538.

Puig, S., N. Andés-Colás, A. García-Molina and L. Peñarrubia. 2007. Copper and iron homeostasis in Arabidopsis: responses to metal deficiencies, interactions and biotechnological applications. Plant Cell Environ. 30: 271-290.

Puppo, A., J. Rigaud and D. Job. 1981. Role of the superoxide anion in the leghemoglobin autoxidation. Plant Sci. Lett. 22: 353-360.

Puppo, A., K. Groten, F. Bastian, R. Carzaniga, M. Soussi, M.M. Lucas, M.R. de Felipe, J. Harrison, H. Vanacker and C.H. Foyer. 2005. Legume nodule senescence: roles for redox and hormone signalling in the orchestration of the natural aging process. New Phytol. 165: 683-701.

Raimunda, D., M. González-Guerrero, B.W. Leeber and J.M. Argüello. 2011. The transport mechanism of bacterial $\mathrm{Cu}(+)$-ATPases: distinct efflux rates adaptated to different function. Biometals. 24: 467-475.

Ranquet, C., S. de-Choudens, L. Loiseau, F. Barras and M. Fontecave. 2007. Cobalt stress in Escherichia coli. The effect on the iron-sulfur proteins. J. Biol. Chem. 282: 30442-30451.

Rea, P.A. 2007. Plant ATP-Binding Cassette transporters. Ann. Rev. Plant Biol. 58: 347-375.

Reyes-Caballero, H., G.C. Campanello and D.P. Giedroc. 2011. Metalloregulatory proteins: Metal selectivity and allosteric switching. Biophys. Chem. 156: 103-114.

Rogers, E.E. and M.L. Guerinot. 2002. FRD3, a member of the multidrug and toxin efflux family, controls iron deficiency responses in Arabidopsis. Plant Cell. 14: 1787-1799.

Roschzttardtz, H., M. Séguéla-Arnaud, J.-F. Briat, G. Vert and C. Curie. 2011. The FRD3 citrate effluxer promotes iron nutrition between symplastically disconnected tissues throughout Arabidopsis development. Plant Cell. 23: 2725-2737. 


\section{Beneficial Plant-microbial Interactions}

Rubio, M.C., E.K. James, M.R. Clemente, B. Bucciarelli, M. Fedorova, C.P. Vance and M. Becana. 2004. Localization of superoxide dismutases and hydrogen peroxide in legume root nodules. Mol. Plant Microbe Int. 17: 1294-1305.

Rubio, M.C., M. Becana, S. Sato, E.K. James, S. Tabata and H.P. Spaink. 2007. Characterization of genomic clones and expression analysis of the three Types of superoxide dismutases during nodule development in Lotus japonicus. Mol. Plant Microbe Interact. 20: 262-275.

Ruel, M. and H. Bouis. 1998. Plant breeding: a long-term strategy for the control of zinc deficiency in vulnerable populations. Am. J. Clin. Nutr. 68: 488S-494.

Sancenon, V., S. Puig, I. Mateu-Andres, E. Dorcey, D.J. Thiele and L. Penarrubia. 2004. The arabidopsis copper transporter COPT1 functions in root elongation and pollen development. J. Biol. Chem. 279: 15348-15355.

Schauer, K., B. Gouget, M. Carriere, A. Labigne and H. de Reuse. 2007. Novel nickel transport mechanism across the bacterial outer membrane energized by the TonB/ExbB/ExbD machinery. Mol. Microbiol. 63: 1054-1068.

Schauer, K., D.A. Rodionov and H. de Reuse. 2008. New substrates for TonB-dependent transport: do we only see the 'tip of the iceberg'? Trends Biochem. Sci. 33: 330-338.

Small, S.K., S. Puri, I. Sangwan and M.R. O'Brian. 2009. Positive control of ferric siderophore receptor gene expression by the Irr protein in Bradyrhizobium japonicum. J. Bacteriol. 191: 1361-1368.

Solioz, M., H.K. Abicht, M. Mermod and S. Mancini. 2010. Response of gram-positive bacteria to copper stress. J. Biol. Inorg. Chem. 15: 3-14.

Stork, M., M.P. Bos, I. Jongerius, N. de Kok, I. Schilders, V.E. Weynants, J.T. Poolman and J. Tommassen. 2010. An outer membrane receptor of Neisseria meningitidis involved in zinc acquisition with vaccine potential. PLoS Pathog 6: e1000969.

Tang, C., A.D. Robson and M.J. Dilworth. 1990. The role of iron in nodulation and nitrogen fixation in Lupinus angustifolius L. New Phytol. 114: 173-182.

Tang, C.X., A.D. Robson, M.J. Dilworth and J. Kuo. 1992. Microscopi evidence on how irondeficiency limits nodule initiation in Lupinus angustifolius 1. New Phytol. 121: 457-467.

Tejada-Jiménez, M., A. Llamas, E. Sanz-Luque, A. Galván and E. Fernández. 2007. A high-affinity molybdate transporter in eukaryotes. Proc. Natl. Acad. Sci. U.S.A. 104: 20126-20130.

Tejada-Jiménez, M., A. Galván and E. Fernández. 2011. Algae and humans share a molybdate transporter. Proc. Natl. Acad. Sci. U.S.A. 108: 6420-6425.

Terry, R.E., K.U. Soerensen, V.D. Jolley and J.C. Brown. 1991. The role of active Bradyrhizobium japonicum in iron stress response of soy-beans. Plant Soil. 130: 225-230.

Tomatsu, H., J. Takana, H. Takahashi, A. Watanabe-Takahashi, N. Shibagaki and T. Fujiwara. 2007. An Arabidopsis thaliana high affinity molybdate transporter required for efficient uptake of molybdate from soil. Proc. Natl. Acad. Sci. U.S.A. 104: 18807-18812.

Velasco, L., S. Mesa, C.A. Xu, M.J. Delgado and E.J. Bedmar. 2004. Molecular characterization of nosRZDFYLX genes coding for denitrifying nitrous oxide reductase of Bradyrhizobium japonicum. Antonie Van Leeuwenhoek. 85: 229-235.

Vercruysse, M., M. Fauvart, S. Beullens, K. Braeken, L. Cloots, K. Engelen, K. Marchal and J. Michiels. 2011. A comparative transcriptome analysis of Rhizobium etli bacteroids: specific gene expression during symbiotic nongrowth. Mol. Plant Microbe Interact. 24: 1553-1561.

Vert, G., N. Grotz, F. Dedaldéchamp, F. Gaymard, M.L. Guerinot, J.F. Briat and C. Curie. 2002 IRT1, an Arabidopsis transporter essential for iron uptake from the soil and the plant growth. Plant Cell. 14: 1223-1233.

Waldron, K.J. and N.J. Robinson. 2009. How do bacterial cells ensure that metalloproteins get the correct metal? Nat. Rev. Micro. 7: 25-35.

Wandersman, C.C. and I. Stojiljkovic. 2000. Bacterial heme sources: the role of heme, hemoprotein receptors and hemophores. Curr. Opin. Microbiol. 3: 215-220.

Wandersman, C.C. and P. Delepelaire. 2004. Bacterial iron sources: From siderophores to hemophores. Annu. Rev. Microbiol. 58: 611-647. 
Wei, Y., H. Li and D. Fu. 2004. Oligomeric state of the Escherichia coli metal transporter YiiP. J. Biol. Chem. 279: 39251-39259.

Yeoman, K.H., F. Wisniewski-Dye, C. Timony, J.B. Stevens, N.G. de Luca, J.A. Downie and A.W. Johnston. 2000. Analysis of the Rhizobium leguminosarum siderophore-uptake gene $f h u A$ : differential expression in free-living bacteria and nitrogen-fixing bacteroids and distribution of an $f h u A$ pseudogene in different strains. Microbiology. 146(Pt 4): 829-837.

Young, J.P., L.C. Crossman, A.W. Johnston, N.R. Thomson, Z.F. Ghazoui, K.H. Hull, M. Wexler, A.R. Curson, J.D. Todd, P.S. Poole, T.H. Mauchline, A.K. East, M.A. Quail, C. Churcher, C. Arrowsmith, I. Cherevach, T. Chillingworth, K. Clarke, A. Cronin, P. Davis, A. Fraser, Z. Hance, H. Hauser, K. Jagels, S. Moule, K. Mungall, H. Norbertczak, E. Rabbinowitsch, M. Sanders, M. Simmonds, S. Whitehead and J. Parkhill. 2006. The genome of Rhizobium leguminosarum has recognizable core and accessory components. Genome Biol. 7: R34.

Zeth, K. and M. Thein. 2010. Porins in prokaryotes and eukaryotes: common themes and variations. Biochem. J. 431: 13-22. 